\title{
Neuroendoscopic Management of Hydrocephalus in Children
}

\author{
ABDUL RAZAQUE MARI, HAMID AKBAR SHEIKH, MUZZAMI LDILBER \\ FEHMIDA ARAB MALLAH, MUHAMMAD ALI JAMALI, SHAMAS RAZA BROHI \\ Department of Neurosurgery \\ Peoples University of Medical \& Health Sciences for Women (PUMHS), Nawabshah \\ DOI: https://doi.org/10.36552/pjns.v23i3.360
}

\begin{abstract}
Objective: To determine the Neuroendoscopic management of hydrocephalus in children.

Materials and Methods: The study was conducted at the Department of Neurosurgery, Peoples University of Medical and Health Science for women Nawabshah from January 2014 to May 2015. All of the patients with hydrocephalus diagnosed on history, clinical examination and CT scan included in the study. Subjects with comorbidities such as uncontrolled diabetes, cardiac diseases or uremia were excluded. Patients with age of 6 months to 13 years either gender were included in the study. Aesculap rigid rod lens neuroendoscope with 0 degree was utilized. Warm ringers were utilized for irrigation, a Fogarty embolectomy catheter was utilized for ETV. Hemostasis was accomplished with irrigation, tamponade or coagulation. Endoscopic third ventriculostomy (ETV) was labeled successfully when characteristics of intracranial hypertension (ICP) clinically improved and the size of ventricular decreased on post-operative CT scan. All the data was recorded in the Proforma.
\end{abstract}

Results: Thirty patients with male to female ration 2.5:1 were administered. Age ranged between 6 months and 12 years with a mean of 22.03 months. There were 15(\%) cases of Tri Ventricular Hydrocephalus, 10 cases of Tetra Ventricular Hydrocephalus. Two cases of Dandy Walker Hydrocephalus, one case of Asymmetrical Ventricles Hydrocephalus and postoperative fever occurred in two subjects. CSF leak appeared in one patient who was managed conservatively. No operative mortality was found.ETV worked effectively for Hydrocephalus treatment in $99.9 \%$ patients included in the study.

Conclusion: Neuroendoscopy is helpful in preventing the practice of shunts for hydrocephalus treatment in children, preventing its cost and complications. Neuroendoscopy is a procedure used in neurosurgery, which is highly frequent for the management of hydrocephalus and intra-ventricular lesions.

Key Words: Hydrocephalus, Neuroendoscopy, children.

\section{INTRODUCTION}

Hydrocephalus is the expansion in the ventricular system of the brain due to poor transfer of CSF (Cerebrospinal fluid) from its formation place to absorption place into systemic circulations. ${ }^{1}$ At present the most frequently practiced therapeutic options for hydrocephalus treatment are Neuroendoscopic surgery and ventriculoperitoneal shunt. Although each option has some benefits and drawbacks, ventriculoperitoneal shunt methods have the high rate of complication. These frequent complications can be presented as a well-known collection of signs and symptoms. Highest frequency characterized by drainage method is infection and obstruction, in spite of the technical advancement accomplished in the development of drainage method. ${ }^{2}$ Each of this complication required surgery to treat raising the mortality and morbidity of this logical thing. Neuroendoscopy is an effective alternative for hydrocephalus management. ${ }^{3}$ Neurosurgeons have been using endoscopy since the early $20^{\text {th }}$ century. During 1918, Walter Dandy being among the earliest surgeons, employed endoscope for choroid plexectomy among four cases of communicating hydrocephalus. ${ }^{4}$ The outcomes were 
poor, because 3 of 4 subjects died. Because of these disappointing outcomes Dandy developed a novel method for fenestration of the floor of the third ventricle via. a sub-frontalmethod. ${ }^{5}$ Though this method remained unpopular because it required an optic nerve sacrifice to afford it. Fay and Grant in 1923, successfully visualized and took the photographs of ventricles' interior area of a child, who had hydrocephalus via a cystoscope. ${ }^{6}$ At the same period of time, a Urologist William Mixter first time in history, carried out an ETV. William Mixter utilized a urethroscope for examining the child's ventricles who had obstructive hydrocephalus; and he fenestrated the third ventricle's floor during this method. ${ }^{12}$ The ETV intended to form a fresh communication between the subarachnoid space and ventricular system by fenestration of the third ventricle's floor. The developers of EVT such as; Patterson, Hoffman, Hirsh and Bergland, suggested that the technique should just be applied to the cases with non-communicating or obstructive hydrocephalus, among whom typical absorption system of CSF is yet present at arachnoid villi. ${ }^{8}$ Certainly, the literature exhibited ETV to be further effective when hydrocephalus is because of compression of fourth ventricle or aqueductal stenosis or aqueduct by tumors. ${ }^{8}$ Factors of hydrocephalus for example meningitis, intraventricular bleeding and subarachnoid bleeding have been considered by a few authors to exclude subjects from ETV. Though, in recent times these have become comparative contraindications taking into consideration the decrease of the mortality and morbidity of ETV. Current publication has revealed an acceptable outcome of ETV than VP Shunt if its symptom was widened to subjects with Cerebrospinal fluid infection, subarachnoid hemorrhage, intraventricular hemorrhage, normal pressure hydrocephalus (NPH), and further communicating hydrocephalus. ${ }^{9-13}$ Gangmei et $\mathrm{al}^{14}$ reported a success rate of ETV up to $73.4 \%$ in $(33 / 45)$ cases with NPH and $60 \%$ in $(12 / 20)$ cases with hydrocephalus (abnormal buildup of CSF) secondary to hemorrhage or infection. The most recent preliminary outcome of a randomized to VP-Shunt (with fixed-pressure valves) to ETV, exhibited that, for VP Shunt, the 12 month improvement rates were $77.0 \%$, while only $50.0 \%$ of subjects who experienced ETV exhibited improvement. The variance was significant, statistically. ${ }^{15}$ Thus, now it is problematic to support ETV as a standard or improve the perception of pathophysiology of non-obstructive hydrocephalus. Besides the etiology of hydrocephalus, success rates of ETV at age $<6$ months are revealed to have greater rates failure. ${ }^{8}$ This study has been conducted to determine the Neuroendoscopic management of hydrocephalus in children aged 6 months to 12 years.

\section{MATERIALS AND METHODS}

\section{Study Design}

The current descriptive case study was conducted at the Neurosurgery department of Peoples University of Medical \& Health Sciences for Women Nawabshah, from January 2014 to May 2015.

\section{Inclusion Criteria}

Patients with hydrocephalus diagnosed on history, clinical examination and CT scan included in the study.

\section{Exclusion Criteria}

Subjects with co-morbidity such as uncontrolled diabetes, cardiac diseases or uremia were excluded.

\section{Data Collection}

Patients with age of 6 months to 13 years old were included in the study. Aesculap rigid rod lens neuroendoscope with 0 degree was utilized. Warm ringers were utilized for irrigation, a Fogarty embolectomy catheter was utilized for ETV. Endoscopic third ventriculostomy (ETV) was labeled successfully when characteristics of intracranial hypertension (ICP) clinically improved and the size of ventricular decreased on post-operative CT scan. All the data was recorded in the Proforma.

\section{Data Analysis}

All data was used for analysis.

\section{RESULTS}

\section{Gender}

Thirty patients with male to male ration $2.7: 1$ were managed.

\section{Age}

Age ranged 6 months to 8 Years with a mean of 22.03 months. 


\section{Type of Hydrocephalus}

There were $16(30.0 \%)$ cases of Tri Ventricular Hydrocephalus, $11(36.7 \%)$ cases of Tetra Ventricular Hydrocephalus. $02(6.7 \%)$ cases of Dandy Walker Hydrocephalus and $1(3.3 \%)$ case of Asymmetrical Ventricles Hydrocephalus (Table 1).

Table 1: Patients distribution according to demographic characteristics $(n=30)$.

\begin{tabular}{|l|l|}
\hline Demographic Characteristics & Frequency (\%) \\
\hline Age groups (years) & \\
\hline$>1$ & $09(30 \%)$ \\
\hline 1 to 3 & $15(50 \%)$ \\
\hline 4 to 6 & $05(16.7 \%)$ \\
\hline 7 to 8 & $01(03.3 \%)$ \\
\hline Total & $30(100 \%)$ \\
\hline Gender & \\
\hline Boys & $21(70 \%)$ \\
\hline Girls & $09(30 \%)$ \\
\hline Total & $30(100.0 \%)$ \\
\hline Hydrocephalus classification & \\
\hline Tri Ventriular Hydrocephalus & $16(53.3 \%)$ \\
\hline Tetra Ventricular Hydrocephalus & $11(36.7 \%)$ \\
\hline Dandy Walker Hydrocephalus & $2(6.7 \%)$ \\
\hline A symetrical Ventricles Hydrocephalus & $1(3.3 \%)$ \\
\hline Total & $30(100.0 \%)$ \\
\hline \hline
\end{tabular}

\section{Operative Procedure}

Right ETV + Septum Pellucidotomy53.3\%, Right ETV + Septum Pellucidotomy + Irrigation 36.7\%, septum pellucidotomy $6.7 \%$ and Asymmetrical Ventricles Hydrocephalus was performed in 1 case (Table 2).

\section{Outcome}

Management success rate was $86.7 \%$. Postoperative fever occurs in 2 subjects. CSF leak appeared in one subject, who was managed conservatively. There was no operative mortality and one case failed due to abnormal anatomy (Table 3).

Table 2: Management procedures $(n=30)$.

\begin{tabular}{|l|c|c|}
\hline Procedure & Frequency & Percent \\
\hline $\begin{array}{l}\text { Right ETV + Septum Pellucidotomy } \\
\text { Right ETV + Septum Pellucidotomy } \\
\text { + Irrigation }\end{array}$ & 16 & 53.3 \\
$\begin{array}{l}\text { septum pellucidotomy } \\
\text { Asymetrical Ventricles } \\
\text { Hydrocephalus }\end{array}$ & 2 & 36.7 \\
Total & 1 & 3.3 \\
\hline
\end{tabular}

Table 3: Neuroendoscopic management outcome $(\mathrm{n}=30)$.

\begin{tabular}{||l|c|}
\hline Postoperative Complications & Frequency (\%) \\
\hline Success rate & $26(86.7 \%)$ \\
Fever & $2(6.7 \%)$ \\
CSF leak & $1(3.3 \%)$ \\
Procedure failed & $1(3.3 \%)$ \\
Total & $30(100.0 \%)$ \\
\hline
\end{tabular}

\section{DISCUSSION}

In our study, twenty one patients were male, and male to female ratio was $=2.5: 1$. In comparison to our results, study conducted by Muga et $\mathrm{al}^{16}$ reported that musculoskeletal system abnormalities highly frequent, after that CNS anomalies, among which the most frequent was hydrocephalus afterward microcephaly and anencephaly and later chromosomal with highly frequent Down's syndrome. Polydactyl was the single most frequent malformation. Males were noted more than females, however, the variance was not significant, statistically. ETV has 2major purposes: the restoration of CSF communication between the subarachnoid and ventricle space; and the reduction of pulsatile stress via raising conformity of the ventricular walls. ${ }^{17}$ ETV was extensively used for hydrocephalus among children as a substitute to CSF shunt primarily in an effort to prevent implantation of foreign entity and to superiorly induce physiological CSF dynamics. Children with shunts depend upon surgery all through their lives. ${ }^{18}$ Therefore, the introduction of neuroendoscopy was enthusiastically 
received. ETV has been a monotonous surgical procedure for the previous 20 years and offers a substitute to the CSF shunt.

In our study Right ETV + Septum Pellucidotomy was done among most of the cases. In comparison to our results, a study conducted by Vulkaran et al ${ }^{19}$ reported that Children can most probably be successful with ETV, currently can be precisely identified and can spare the longstanding complications associated with CSF shunting. Another study conducted by Javadpour et $\mathrm{al}^{20}$ also reported in their results that throughout the follow-up phase, ETV remained evident among $7(33 \%)$ of subjects $(n=21)$. Their results also suggested that selective application of ETV as a primary administration in babies with hydrocephalus is reliable and can diminish shunted populace of all freshly diagnosed hydrocephalic babies by around $21.0 \%$. Another study conducted by Yadav et $\mathrm{al}^{21}$ also reported that ETV was rather safe and useful in typical birth weight full term infants, however in premature low birth weight infants the outcomes were poor.

The results of our study showed that management success rate was $86.7 \%$. Postoperative fever occurs in 2 subjects. CSF leak occurred in 1subject who was managed conventionally and no operative mortality was found and one case failed due to abnormal anatomy. A study conducted by Brohi et $\mathrm{al}^{22}$ exhibited $68.0 \%$ efficacy; which is somewhat lesser than this study, however no significant variance exist, statistically. Long period of follow-up is possibly the factor for slightly lesser success rate within the study by Brohiet al. ${ }^{22}$ Further studies such as Sufianov et $\mathrm{al}^{23}$ recounted $71.40 \%$ efficacy; which is highly closer to the general efficacy in this study. In comparison to our results, a study conducted by Simone Peraioet et $\mathrm{al}^{24}$ reported that neuroendoscopy contributes significantly in the longstanding administration of complex hydrocephalus, considerably reducing the shunt revision rate and the number of shunts. The total postoperative complication rate was $28.0 \%$ (2.90\%: subdural collection; $8.80 \%$ : shunt malfunction; 16.10\%: shunt infection). At final clinical follow-up, $65.0 \%$ kids had just 1 shunt, $25.0 \%$ had a twofold ventricular catheter, and $10.0 \%$ were shunt free. Similar results were also seen in a study conducted by de Ribaupierre et $\mathrm{al}^{25}$ in which the ETV failure rates were $26.0 \%$ and that of VP shunt was $42.0 \%$ at followup period of 5 years. The similar trend was observed in further series. Kulkarni et $\mathrm{al}^{26}$ also documented that the RR of ETV failure was initially greater than CSF shunt. Though, the risk turned gradually lower at around 3 months after the process, and was around $50 \%$ the risk of shunt failure at 2 years. Other reports also have found similar results. ${ }^{27,28}$

\section{CONCLUSION}

Neuroendoscopy is helpful in preventing the practice of shunts for hydrocephalus treatment in children, preventing its cost and complications. Neuroendoscopy is a technique used in neurosurgery, which is highly frequent for the management of hydrocephalus and intra-ventricular lesions. However, the financial implications are a concern and the reason for its unavailability in most of the public sector hospitals. More similar studies are required on this management.

Address for Correspondence: Dr. Abdul Razaque Mari Department of Neurosurgery, PUMHS, Nawabshah Email:razakmari@yahoo.com

\section{Additional Information}

Disclosures: Authors report no conflict of interest.

Human Subjects: Consent was obtained by all patients/ participants in this study.

Conflicts of Interest:

In compliance with the ICMJE uniform disclosure form, all authors declare the following:

Financial Relationships: All authors have declared that they have no financial relationships at present or within the previous three years with any organizations that might have an interest in the submitted work.

Other Relationships: All authors have declared that there are no other relationships or activities that could appear to have influenced the submitted work

\section{REFERENCES}

5. Hazel $\mathrm{C}$ Jones and Petra $\mathrm{M}$ Klinge. Hydrocephalus 2008, 17-20th September, Hannover Germany: a conference report. Cerebrospinal Fluid Research, 2008; 5: 19.

1. Harold L Rekate. The definition and classification of hydrocephalus: a personal recommendation to stimulate debate. Cerebrospinal Fluid Research, 2008; 5: 2.

2. Drake, James M. MB, BCh; Kestle, John R.W. MD; Milner, Ruth MSc; Cinalli, Giuseppe MD; Boop, Frederick MD; Piatt, Joseph Jr. MD; Haines, Stephen MD and Collaborators. Randomized Trial of 
Cerebrospinal Fluid Shunt Valve Design in Pediatric Hydrocephalus. Neurosurgery, 1998; 43 (2): 294-303.

1. Dirk F., Frank D., Hilmar K., Alexandra W. and Ernst G. Neuroendoscopic Tratament of Idiopathic Occlusion of the Foramen of Monro in Adults. Neurol Med Chir (Tokyo), 2002; 42: 81-85.

3. Stan H, Kiss PA, Stan A, Florian IS. Neuroendoscopic surgery in hydrocephalus. Romanian Neurosurgery, 2012; 19 (4): 265-72.

4. Dandy WE. Extirpation of the choroid plexus of the lateral ventricles in communicating hydrocephalus. Ann Surg. 1918; 68 (6): 569-79.

5. Dandy WE. An operative procedure for hydrocephalus Johns Hopkins Hosp Bull. 1922; 33: 189-90.

6. Fay T, Grant FC. Ventriculostomy and intraventricular photography in internal hydrocephalus. JAMA. 1923; 80: 461-3.

7. Mixter WJ. Ventriculoscopy and puncture of the floor of the third ventricle. Boston Med Surg J. 1923; 188: $277-8$.

8. Ling JM, Tiruchelvarayan R. A review of endoscopic treatment of hydrocephalus in paediatric and adult patients. Proceedings of Singapore Healthcare, 2013; 22 (3): 203-1.

9. Shimizu T, Luciano MG, Fukuhara T. Role of endoscopic third ventriculostomy at infected cerebrospinal fluid shunt removal. J Neurosurg Pediatr. 2012; 9 (3): 320-6.

10. Paidakakos N, Borgarello S, Naddeo M. Indications for endoscopic third ventriculostomy in normal pressure hydrocephalus. Acta Neurochir Suppl. 2012; 113: 1237.

11. Oertel JM, Mondorf Y, Baldauf J, Schroeder HW, Gaab MR. Endoscopic third ventriculostomy for obstructive hydrocephalus due to intracranial hemorrhage with intraventricular extension. J Neurosurg. 2009; 111 (6): 1119- 26.

12. Fukuhara T, Shimizu T, Namba Y. Limited efficacy of endoscopic third ventriculostomy for hydrocephalus following aneurysmal subarachnoid hemorrhage. Neurol Med Chir. (Tokyo), 2009; 49 (10): 449-55.

13. Rangel-Castilla L, Barber S, Zhang YJ. The role of endoscopic third ventriculostomy in the treatment of communicating hydrocephalus. World Neurosurg. 2012; 77 (3-4): 555-60.

14. Gangemi M, Maiuri F, Colella G, Magro F, Seneca V, de Divitiis E. Is endoscopic third ventriculostomy an internal shunt alone? Minim Invasive Neurosurg. 2007; 50 (1): 47-50.

15. Pinto FC, Saad F, Oliveira MF, Pereira RM, Miranda FL, Tornai JB, et al. Role of endoscopic third ventriculostomy and ventriculoperitoneal shunt in idiopathic normal pressure hydrocephalus: Preliminary results of a randomized clinical trial. Neurosurgery, 2013; 72 (5): 845-53.
16. Muga RO, Mumah SCJ, Juma PA. Congenital malformations among newborns in Kenya, Afr $\mathbf{J}$ food Agri Nutr Dev. 2009; 19: 819-29.

17. Greitz D. Radiological assessment of hydrocephalus: new theories and implications for therapy. The neuroradiology journal, 2006; 19 (4): 475-95.

18. Simon TD, Riva-Cambrin J, Srivastava R, Bratton SL, Dean JM, Kestle JR, Hydrocephalus Clinical Research Network: Hospital care for children with hydrocephalus in the United States: utilization, charges, comorbidities, and deaths. J Neurosurg Pediatr. 2008; 1: 131- 137.

19. Kulkarni, Abhaya V., et al. Endoscopic third ventriculostomy in the treatment of childhood hydrocephalus. The Journal of pediatrics, 2009; 254259.

20. Javadpour M, Mallucci C, Brodbelt A, Golash A, May P. The impact of endoscopic third ventriculostomy on the management of newly diagnosed hydrocephalus in infants. Pediatric neurosurgery, 2001; 35 (3): 131-5.

21. Yadav Y R, Jaiswal S, Adam N, Basoor A, Jain G. Endoscopic third ventriculostomy in infants. Neurol India, 2006; 54: 161-3.

22. Brohi SR, Brohi AR, Sidiqui MA, Mughal SA, Saeed S. Outcome of endoscopic third ventriculostomy in hydrocephalus. J Surg Pak. 2010 Jan; 15 (1): 25-8.

23. Sufianov AA, Sufianova GZ, Lakimov IA. Endoscopic third ventriculostomy in patients younger than two years: outcome analysis of 41 cases. J Neurosurg Pediatr. 2010; 5: 392-401.

24. Simone Peraio, Mohamed Mohsen Amen, Nabil Mansour Ali, Ahmed Zaher, Ahmed Nageeb Mohamed Taha, Gianpiero Tamburrini Corrigendum to 'Endoscopic Management of Pediatric Complex Hydrocephalus. World Neurosurgery, 2018; 119: 482490.

25. Ribaupierre S, Rilliet B, Vernet O, Regli L, Villemure JG. Third ventriculostomy vs. ventriculoperitoneal shunt in pediatric obstructive hydrocephalus: results from a Swiss series and literature review. Child's Nervous System, 2007; 23 (5): 527-33.

26. Kulkarni AV, Drake JM, Kestle JR, Mallucci CL, Sgouros S, Constantini S, Canadian Pediatric Neurosurgery Study Group : Endoscopic third ventriculostomyvs cerebrospinal fluid shunt in the treatment of hydrocephalus in children: a propensity score-adjusted analysis. Neurosurgery, 2010; 67: 58893.

27. Sainte Rose C: Third ventriculostomy, in Manwaring $\mathrm{KH}$, Crone KR, editors. (eds): Neuroendoscopy. New York, Mary Ann Liebert, 1992: pp. 47-62.

28. Tuli S, Alshail E, Drake J: Third ventriculostomy versus cerebrospinal fluid shunt as a first procedure in pediatric hydrocephalus. Pediatr Neurosurg. 1999; 30: $11-15$. 


\begin{tabular}{|c|c|c|c|}
\hline \multicolumn{4}{|c|}{ AUTHORSHIP AND CONTRIBUTION DECLARATION } \\
\hline Sr.\# & Author's Full Name & Intellectual/Contribution to Paper in Terms of: & \multirow{3}{*}{$\begin{array}{l}\text { Signature by the } \\
\text { author(s) }\end{array}$} \\
\hline 1. & $\begin{array}{l}\text { Abdul Razaque Mari } \\
\text { (Main/Principal Author). }\end{array}$ & $\begin{array}{l}\text { 1. Proposed topics and Basic Study Design, } \\
\text { methodology. }\end{array}$ & \\
\hline 2. & $\begin{array}{l}\text { Hamid Akbar Sheikh } \\
\text { (2nd Author) }\end{array}$ & $\begin{array}{l}\text { 2. Paper writing, referencing, Data Calculations and } \\
\text { quality insurer }\end{array}$ & \\
\hline 3. & $\begin{array}{l}\text { Muzzamil Dilber } \\
\text { (3rd Author) }\end{array}$ & 3. Data collection and calculations & \\
\hline 4. & $\begin{array}{l}\text { Fehmida Arab Mallah } \\
\text { (4th Author) }\end{array}$ & 4. Analysis of data and interpretation of results etc. & \\
\hline 5. & $\begin{array}{l}\text { Muhammad Ali Jamali } \\
\text { (5th Author) }\end{array}$ & 5. Literature review and manuscript writing & \\
\hline 6. & $\begin{array}{l}\text { Shamas Raza Brohi } \\
\text { (6th Author) }\end{array}$ & 6. Study Design and methodology & \\
\hline
\end{tabular}

Date of Submission: 06-07-2019

Date of Revision: 30-07-2019

Date of Online Publishing: 25-09-2019

Date of Print: 30-09-2019 